\title{
Pharyngeal Necrotic Lesion
}

National Cancer Institute

\section{Source}

National Cancer Institute. Pharyngeal Necrotic Lesion. NCI Thesaurus. Code C78554.

A necrotic process affecting the pharynx. 